DOI: $10.5007 / 1981-1322.2010 v 5 n 1 p 1$

\title{
ESTRATÉGIAS PARA RESOLUÇÃO DE PROBLEMAS MATEMÁTICOS POR TRÍADES DE ALUNOS COM E SEM RELAÇÃO DE AMIZADE ${ }^{1}$ STRATEGIES TO THE RESOLUTION OF MATHEMATICAL TASKS BY TRIADS OF STUDENTS WITH AND WITHOUT REGARD FOR FRIENDSHIP
}

\section{Maria do Carmo Silva carmo.lobato@yahoo.com.br}

Marinalva Silva Oliveira marinalvaoliveira@yahoo.com.br

\section{Resumo}

O propósito desta pesquisa foi descrever e analisar as estratégias utilizadas por tríades de alunos com e sem relação de amizade durante a participação guiada em tarefas matemáticas. Participaram 24 alunos da $3^{\text {a }}$ série do Ensino Fundamental, agrupados em quatro tríades com relação de amizade (TCRA) e quatro tríades sem relação de amizade (TSRA). A seleção para agrupá-los ocorreu através de entrevista buscando conhecer o vínculo afetivo. As interações foram registradas com filmadora e gravador e, posteriormente transcritas e analisadas. Os resultados mostraram que as tríades utilizaram uma multiplicidade de estratégias algorítmicas (EA) que envolviam seguimento de regras e estratégias não algorítmicas (ENA), caracterizadas pela ausência de regras matemáticas explícita. As estratégias algorítmicas (EA) foram ainda divididas em Orais e Escritas. Observou-se que tanto as TCRA quanto as TSRA utilizaram como estratégia comum à contagem utilizando os dedos e escrita. A diferença analisada nas estratégias foi à utilização de ENA por cálculo mental pelas TSRA, ou seja, os alunos buscavam resolver de forma individual e não expressavam para seus parceiros as estratégias utilizadas, ensejando desta forma, que o significado atribuído ao outro e a tarefa são possibilitadores ou não de interação entre os alunos.

Palavras-chave: Estratégias Matemáticas. Tríades de alunos. Participação Guiada. Afetividade.

1 Apoio: $\mathrm{CNPq}$ 


\section{Introdução}

Nas últimas décadas as pesquisas na área da educação matemática têm destacado o processo de construção de conceitos e uso de estratégias aritméticas por crianças durante a interação professor-aluno. Entretanto, no contexto de sala de aula ocorrem também interações entre alunos, que proporcionam possibilidades de construção do conhecimento, com interações ricas em ações verbais e, consequientemente, aprendizagem, possibilitando alguns tipos de envolvimentos e restringindo outros, dependendo do significado atribuído ao outro e à tarefa (OLIVEIRA, 2002; SIMÃO, 2000, 2002). Rogoff $(2005$, 1998) destaca o conceito de participação guiada para entender esses processos e sistemas de envolvimento entre as pessoas à medida que se comunicam e coordenam esforços ao participarem de atividades culturais, onde se inclui a interação face-a-face como meio para construção de conhecimento. Segundo Rogoff $(2005,1998)$ quando uma criança participa de uma atividade seu envolvimento é de uma só vez individual e social. Social porque seu desenvolvimento acontece durante a interação com seu grupo cultural, e tornam-se individuais à medida que cada uma se apropria. Nesse sentido, à medida que a interação social vai acontecendo às pessoas têm possibilidades de se apropriarem de um repertório de saberes, valores e práticas sociais que farão parte de seu legado cultural. Os usos posteriores destes conhecimentos dependerão do contexto, das pessoas envolvidas e das relações interpessoais (SIMÃO et al, 2004).

Neste sentido, durante participação de alunos em atividades em grupo, cada um poderá regular seu próprio papel e dos outros através da estruturação de limites e oportunidades para o envolvimento na tarefa. Deste modo, através da participação guiada por parceiros sociais, às pessoas se modificam e no processo se tornam preparadas para fazerem parte de atividades similares e ao fazer parte os mesmos poderão fazer contribuições freqüentes com ações concretas ou esforços para entender as ações e idéias dos outros.

Seguindo este contexto, entende-se que a interação de alunos em atividades matemáticas pode proporcionar uma perspectiva para entender como "um" ou mais alunos podem contribuir para o desenvolvimento de competências no outro e em si mesmo. Interagir com diferentes parceiros durante a resolução de tarefas matemáticas pode envolver negociações, argumentações, contra-argumentações, conflitos sociocognitivos, e assim são construídas oportunidades para uma apropriação participatória de conhecimentos matemáticos (NEVES; CARVALHO, 2006; OLIVEIRA, SILVA, MENDONÇA, 2007).

As investigações realizadas sobre os processos de participação dos alunos em interações facea-face têm evidenciado que quando estes têm possibilidades de trocar pontos de vista, discutir resoluções, negociarem estratégias aritméticas, orientar o parceiro sobre o desenrolar da atividade ou assistir ao argumento do outro, propicia-se o desenvolvimento tanto de competências matemáticas, quanto sociais, cognitivas, afetivas e lingüísticas (OLIVEIRA, 2003, 2001; CARVALHO; CÉSAR, 2002). Esta compreensão tem contribuído para a transformação da forma de pensar o ensino da matemática no contexto da sala de aula.

Segundo Carvalho (2001) quando no contexto escolar há ausência ou baixa competência verbal do aluno em expor seu pensamento gera nos professores expectativas negativas sobre seu potencial, corroborando assim resultados negativos. Para tanto pesquisas (CÉSAR, 2000; FREITAS, 2005) demonstram que talvez faltem aos alunos tarefas que representem algum desafio, que o estimule a utilizar conhecimentos de forma relacional. Nesta linha, segundo Freitas (2005), a forma como a escola vem ensinando desconsidera as ferramentas utilizadas pelos alunos para interpretar os enunciados das questões, tornando dicotômicas as estratégias de ensino e aprendizagem da matemática formal e informal. Desta forma o objetivo principal do aluno em sala de aula, além de ser aprovado no final do ano com boas médias, é resolver os problemas matemáticos para acertar, mostrando à professora e aos colegas que memorizou 
uma determinada regra. A reversão desse quadro é fundamental para que os alunos efetivamente possam compreender seu próprio desenvolvimento diante da tarefa. Nesse sentido são importantes as contribuições de Cavalcanti (2001, apud por FREITAS, 2005) quando diz que as resoluções de problemas matemáticos pelas crianças devem receber especial atenção, principalmente em função dos modos pelos quais elas resolvem.

Silveira (2005) reafirma que as regras matemáticas são universais e tem sentido único, entretanto, o modo como são interpretadas serão individuais e dependerão dos conceitos já construídos pelos alunos, uma vez que tais conceitos fazem parte dos diferentes contextos vivenciados. Em caso de "erros" durante a interpretação da regra, cabe ao professor intervir e confrontar essa interpretação com a lógica da matemática, e na confrontação o professor tem a oportunidade de ensinar melhor quando entende a lógica do aluno, e este aprende quando entende sua lógica e da matemática.

Santos (2006) ainda enfatiza que ao invés de inúmeros problemas com a mesma lógica, devese oferecer aos participantes diversas lógicas nos problemas para que possa reconhecer as características de cada um, adotando a(s) estratégia(s) que melhor se adeque(m) à resolução. Ainda para esta autora, o trabalho em grupo favorece a construção de conceitos matemáticos por parte da criança através de um processo metacognitivo que é a argumentação das suas estratégias para o outro, ensejando desenvolvimento cognitivo, social e afetivo, permitindo descobrir em si e nos pares capacidades que desconheciam, implicando um processo de desenvolvimento de competências (OLIVEIRA, 2002; CÉSAR, 2000; CARVALHO, 2003).

De acordo com Freitas (2005), para o aluno evoluir na apropriação de conceitos matemáticos no contexto de sala de aula faz-se necessário, também, que os problemas matemáticos obedeçam a uma ordem hierárquica do grau de dificuldades, apresentando-se como desafios a serem superados. Para Vergnaud (1991, apud FREITAS, 2005) "problemas matemáticos" são situações que demandam solução, e originam aos alunos a necessidade de descobrir relações e explicá-las, de modo que possam elaborar hipóteses e verificá-las. Já na concepção de Charnay (2001, apud FREITAS, 2005) problemas matemáticos são construídos a partir do tripé situação-aluno-meio, sendo que o problema existirá se o aluno percebê-lo como um obstáculo a ser superado. Diante disso, observa-se que nas conceituações de Vergnaud e Charnay, o aluno precisa perceber o problema como um desafio, e assim criar meios para solucioná-lo. E esses meios não se encontram isolados das circunstâncias e nem do contexto que o aluno está inserido.

Silveira (2005) enfatiza que o aluno ao interpretar um problema matemático pode construir e reconstruir conceitos matemáticos (criando suas próprias estratégias para resolver), e a aplicação dessas estratégias mudarão de acordo com a situação apresentada e o contexto no qual está envolvido.

Para Oliveira (2002) estratégia é o processo pelo qual o aluno atinge uma meta, resolve uma situação ou um conjunto delas ou, resolve um problema matemático utilizando um ou vários elementos, dependendo do tipo de problema, do contexto cultural e do significado atribuído. Assim as estratégias podem ser algorítmicas (EA) e não algorítmicas (ENA), as EA são definidas como o processo que envolve o seguimento de regras "algorítmicas" para a solução de problemas as quais podem ser orais ou escritas. Já as ENA não envolvem seguimento de regras "algorítmicas" para se obter a solução do problema (OLIVEIRA; TOURINHO, 2001).

Ainda nesta perspectiva, Oliveira e Tourinho (2001) entendem que os algoritmos matemáticos podem ser interpretados como regras que controlam o comportamento matemático eficiente. Neste sentido a eficiência seria definida através dos acertos alcançados, como é enfatizado pela escola, desvinculando-se das experiências do aluno.

Nos estudos sobre $E A$ as classificações foram: 1) Contagem Oral Unidade por Unidade (UU), nesta o aluno verbaliza a primeira parcela e conta nos dedos a partir dos algarismos da segunda parcela; 2) Contagem Escrita com Recursos Gráficos (CE), se recorre a algum 
recurso escrito para representar o pensamento; 3) Montagem da Operação (MO), quando se retira o valor das parcelas do enunciado do problema e arma a conta na vertical ou horizontal; 4) Memorização (M), quando se explica a estratégia utilizada justificando que memorizou de uma situação anterior (OLIVEIRA; TOURINHO, 2001); 6) Composição (C), o aluno a partir de um dos valores junta sucessivamente certas quantidades até chegar à solução; 7) Contagem com Utilização de Recursos Externos (CRE), quando se representa as unidades das parcelas por meio dos dedos e em seguida são contados o número total de unidades ou se conta o valor de uma das parcelas a partir de outra parcela até atingir o valor total; 8) Contagem crescente a partir de uma das parcelas até atingir o total (CC), o aluno conta a partir de uma das parcelas, e utiliza como padrão valores iguais ou maiores que duas (CORREA; MOURA, 1997); 9) Decomposição (D): transformação do(s) termo(s) da soma ou subtração por sua decomposição em números que facilitem a operação; 10) Decomposição com Representação Gráfica (DRG), ocorre a transformação do(s) termo(s) da soma ou subtração por sua decomposição em números que facilitem a operação pensamento; 11) Composição com Representação Gráfica (CRG), a partir de um dos valores o aluno vai juntando sucessivamente certas quantidades de forma a chegar à solução usando também formas escritas para representar seu pensamento (CORREA ; MOURA, 1997; OLIVEIRA ; TOURINHO, 2001); 12) Estratégia de produção escrita (EPE) são aquelas em que se recorre a textos, questionários por eles criados ou a um plano de como executar a tarefa proposta e 13) Estratégia algébrica (EAL) pressupõe-se que os alunos são capazes de pôr em equação um problema e resolvê-lo (CARVALHO, 2001).

Já as ENA encontradas na literatura foram: 1) Estratégia por Tentativa e Erro (TE), que consiste em experimentar diversas soluções e verificar qual delas corresponde ao valor ou resposta pretendido pelo aluno sem que ele explique os meios utilizados para encontrar tal resultado (CARVALHO, 2001); 2) Valor Numérico Correspondente por Provável Cálculo Mental (VCM), quando o indivíduo apenas expressa o resultado do problema sem verbalizar como chegou ao resultado (FREITAS, 2005); 3) Memorização (M), quando se explica a estratégia utilizada justificando que memorizou de outra situação e 4) Operação Inversa (OI): o aluno identifica a operação no problema e resolve-o utilizando a operação inversa (OLIVEIRA; TOURINHO, 2001). Através dos estudos sobre estratégias verificou-se que existem inúmeras formas de resolver problemas matemáticos, que são construídos a partir das relações do participante com a cultura e com as outras pessoas.

E para ampliar os estudos que vêm sendo realizados neste campo, a proposta desta pesquisa é descrever e analisar as estratégias utilizadas por tríades de crianças com e sem relação de amizade durante a participação guiada em tarefas matemáticas. Os problemas matemáticos apresentados aos alunos participantes da pesquisa foram classificados como não-habituais. Segundo Carvalho (2001) neste tipo de tarefa não-habitual os alunos não encontram regras pré-definidas para utilização de estratégias, isto pode possibilitar o uso de diferentes estratégias para sua resolução.

\section{Metodologia}

\section{Participantes}

Participaram desta pesquisa 24 alunos da $3^{\mathrm{a}}$ série do Ensino Fundamental de uma Escola da rede Pública de Macapá, agrupados em quatro tríades com relação de amizade (TCRA) e quatro tríades sem relação de amizade (TSRA).

\section{Materiais}

Papel, lápis, borracha, filmadora digital, CD para filmadora digital, mini-gravador e mini-fita cassete. 


\section{Obtenção de informações empíricas}

Inicialmente foi solicitada autorização da Escola para desenvolvimento da pesquisa. Obtida a concordância, foi realizado o contato com as professoras da $3^{\mathrm{a}}$ série do ensino fundamental para verificar quais os conteúdos de matemática já haviam sido trabalhados na de sala de aula. Participaram da obtenção de informações empíricas 24 alunos da $3^{\mathrm{a}}$ série do ensino fundamental, agrupados em quatro tríades com relação de amizade (TCRA) e quatro tríades sem relação de amizade (TSRA). A seleção para agrupá-los nas tríades ocorreu através de entrevista, cujo propósito foi conhecer sobre o vínculo afetivo com seus colegas, bem como o tempo de amizade e se gostavam ou costumavam realizar trabalhos juntos. A partir das indicações na entrevista foram formadas as TCRA. Já as TSRA formaram-se com alunos que não se indicaram na entrevista. Posteriormente, as tríades foram encaminhadas a uma sala separada em dias e horários diferentes com o propósito de resolver cinco problemas matemáticos em tarefas não habituais, diferentes quanto ao enunciado, mas semelhantes quanto ao aspecto conceitual. As interações entre as crianças foram registradas com o auxílio de câmera de vídeo e um mini-gravador com o consentimento dos responsáveis pelas as crianças, das próprias crianças, da professora e da direção escolar. Cada tríade participou de uma sessão e durante a sessão os alunos foram solicitados para que tentassem solucionar os problemas matemáticos sempre verbalizando para os outros as dúvidas, as estratégias e as metas utilizadas no decorrer da resolução dos problemas. Após essas explicações, foi entregue a cada tríade um papel com problemas a serem solucionados por escrito, colocando um lápis e um papel à disposição dos mesmos, objetivando propiciar condições que pudessem provocar a realização conjunta dos problemas. Após a obtenção das informações empíricas, as fitas foram transcritas e analisadas segundo o método microgenético. Segundo Góes (2000) esse método caracteriza-se por um conjunto de ações que visam analisar o fenômeno minuciosamente em todo seu processo, em vez do processo em si, levando em consideração a seqüência temporal, bem como as mudanças que ocorriam no aluno e no meio. Assim, os critérios utilizados para análise visavam compreender o processo de negociação, quais estratégias foram comuns e diferentes nas TCRA e TSRA, e como a afetividade poderia interferir durante a interação entre os alunos.

\section{Resultados e Discussão}

Os resultados mostraram que as tríades utilizaram uma multiplicidade de $E A$ que envolviam o seguimento de regras e ENA que não envolviam seguimento de regras. As $E A$ foram ainda divididas em Orais e Escritas:

As Orais foram classificadas em CRE; CC; As Escritas: CE; D; C; MO. As ENA apareceram somente na forma oral: VCM e TE.

Abaixo será apresentada a tabela 1 com o demonstrativo das estratégias utilizadas pelas tríades com e sem relação de amizade. 


\begin{tabular}{|c|c|c|c|c|}
\hline Tríades & \multicolumn{4}{|c|}{ Estratégias matemáticas } \\
\hline \multirow{5}{*}{ TCRA } & $T C R A 1$ & $T C R A 2$ & $T C R A 3$ & $T C R A 4$ \\
\cline { 2 - 5 } & D; CRE; & TE; CRE; & TE; CRE; & CE; TE; CRE; \\
& CC; CE; & CC; CE; & CC; CE; & CC; C; MO \\
& MO & MO & MO & \\
\hline \multirow{5}{*}{ TSRA } & $T S R A 1$ & $T S R A 2$ & $T S R A 3$ & $T S R A 4$ \\
\cline { 2 - 5 } & CRE; CC; & TE; CRE; & TE; CRE; & TE; CRE; CC; \\
& CE; MO & CC; CE; & CC; CE; & CE; MO; VCM \\
& & MO; & MO; & \\
& & VCM & VCM & \\
& & & & \\
\hline
\end{tabular}

Tabela 1- Demonstrativo de estratégias utilizadas pelas tríades

Na tabela 1 constata-se que houve $E A$ orais e escritas comuns utilizadas tanto nas TCRA e TSRA: $C R E ; C C ; C E$ e MO. Já as estratégias ENA comuns utilizadas tanto pela TCRA2, TCRA3, TCRA4 quanto pela TSRA3, TSRA4 foiTE. E também foram verificadas outras $E A$ escritas: a TCRA1 utilizou: $D$ e a TCRA4 utilizou a $C$ na resolução de problemas. E as TSRA2, TSRA3, TSRA4 utilizaram ENA como VCM.

Nessa descrição foram observadas com frequiência, tanto nas TCRA quanto nas TSRA, a utilização de estratégias comuns em problemas de adição e subtração que foi à contagem tanto com representações nos dedos e/ou gráficas. Para Vergnaud (1985, apud por CORRÊA; MOURA, 1997) os alunos ao representarem as estratégias usando os dedos ou escrita buscam explicitar mais facilmente os significados presentes nos processos que envolvem a resolução da tarefa, construindo desta forma uma representação mental de como haviam pensado.

Abaixo serão apresentados trechos do diálogo de duas tríades que demonstraram a utilização de $E A$ por contagem tanto oral quando escrita.

Ex: TCRA $4:(C R E)$

20. A: é 6 ( confere nos dedos)

21. D: é 6

22. D: Não é 3 mais 3

23. A:( confere no dedo) 1,2,3,4,5,6

24. D: (...) escreve aí.

TSRA4: $(C R E)$

64. $E: 8 \mathrm{com} 17$.

65. (I tenta conferir, mais é interrompido por $E$ ).

66. E: 17,18,19,20,21,22,23,24,25,26 (Confere nos dedos, mostrando para os colegas).

67. I: (Confirma) 26, 26.

Nesses dois trechos do diálogo das tríades observa-se a utilização da estratégia $C R E$, tendo em vista que os alunos representaram através dos dedos as unidades das parcelas, e contavam o número de unidades até chegar o total (CORREA; MOURA, 1997). Outra estratégia utilizada com bastante frequiência nas tríades foi $C E$. Também se observa que durante a discussão entre os alunos havia o envolvimento de estratégias por contagem oral e escrita na tentativa de explicar ao colega outra estratégia para solucionar o mesmo problema. 
Ex: TCRA1: $(C E)$ e (CRE)

41. M: (faz pauzinho) 1,2,3,4,5,6

42. (L interrompe): hum caramba...

43. M: (continua)7,8,9,10,11,12,13,14,15,16,17,18,19,20,21,22, Quanto?

42. $E: 81$

43. $M:($ se senta na cadeira $)$

44. E: (mostra para L no dedo) 86, tem 8 tira 2 fica 6

45. $M$ : (ignora e continua a contar).

46. L: (fala para $M)$ é 86

47. M: é 86, é só colocar (mostra no dedo) o 8 aqui né?( falando para E)

48. E: (confere no dedo e mostra a M) só colocar o 8 tira 2 fica 6.

49. M: é só colocar o 8, tira 2 fica 6.

50. L: (ri) fica 6.

51. E: (confirma) 86, ele fica teimando aí.( se referindo a $M$ )

52. L: (confirma) 86.

Através do diálogo entre os alunos foi possível verificar que as representações orais e escritas forneceram "caminhos" sobre como a criança pensou, como agiu, como exprimiu suas idéias diante do outro, viabilizando uma troca de experiência entre os alunos, ampliando seus vocabulários matemáticos e lingüísticos através da verbalização e representação gráfica das estratégias. Desta forma infere-se que o contexto onde as participações acontecem não é neutro, nem tão pouco limitado ao ambiente físico, uma vez que a construção e discussão de conceitos matemáticos aconteciam na medida em que os alunos representavam verbalmente, ou através da escrita, ou os dois ao mesmo tempo, as estratégias matemáticas utilizadas. Essas representações escritas e orais podem ser analisadas como as interpretações das regras matemáticas realizadas pelos alunos.

A estratégia contagem com representações nos dedos e/ou gráficas foram as mais utilizadas pelas TCRA e TSRA. Segundo Correa e Moura (1997) essas estratégias são comuns porque são as formas mais simples que a própria escola ensina, e também as crianças se apropriam ao longo de suas participações em atividades culturais. Assim se tornou mais evidente durante a participação em tríades porque os alunos acabavam mostrando para seus colegas como chegaram à resolução do problema ou mesmo para convencer seus colegas que o resultado estava correto, segundo sua interpretação.

Desta maneira, quando o aluno tem a oportunidade de dialogar com outro sobre estratégias, ambos têm a oportunidade de co-construírem significados, e isso é benéfico para a apropriação ou reconstrução de novos conceitos matemáticos que os ajudam a compreender melhor a lógica da matemática e sua própria lógica durante a resolução. Silveira (2005) enfatiza, que quando os alunos não conseguem explicar a resolução de um problema matemático verbalmente, utilizam à escrita como meio de compreensão de sua própria interpretação. Neste caso como a atividade matemática foi apresentada para as tríades, a verbalização das estratégias ou representação escrita também serviu para viabilizar o acesso, e até mesmo o entendimento do outro durante a resolução do problema.

Outra EA representada através da escrita e comum nas TCRA e TSRA foi a $M O$. Esta estratégia é uma das mais ensinadas no contexto da sala de aula, sendo também utilizada nos livros didáticos.

Para exemplificar o uso da $M O$, abaixo segue um trecho do diálogo entre os alunos da TSRA2. 
Ex: TSRA2: $(M O)$

39. A e V: (Falam juntos) Bota o 6 primeiro.

40. $V:$ : 0 ?

41. J: É 260 em baixo do 6 (repete) 260 em baixo do 6. Agora vai somando.

42. A: (Aponta para o papel) dá 3.

43. J: Dá 6 ("A”olha para “J”) (...) não, não, é de traz pra frente. 6 e 6 dá $6.6 x 6$ (fica pensativo) 11 é 3 .

44. V: Tá aqui.

No trecho do diálogo acima entre os alunos da TSRA2 percebe-se a descrição passo a passo da $M O$. Nesta descrição da estratégia os alunos registram no papel a primeira parcela e em seguida verbalizam a outra parcela para serem montadas e calculadas de forma vertical. Já a $E A$ por $D$ é observada somente na TCRA1, abaixo segue a seqüência de diálogo:

Ex: TCRA1: $(D)$

27. E: (tenta convencer L) $4 \times 7$ é 28 ( mostra no dedo)

28. E: (confere no dedo) 7 com 7 são " 14 " com mais "7” é 21 com +1 são 29

29. M: Então é 29 reais (Puxa o lápis de E)

30. E: Escreve aí (se referindo a M). Ele gastou 29 reais.

Nesse momento de interação observa-se que aluno $E$ transforma uma operação multiplicativa em soma de parcelas (e.g 27 e 28), e soma os valores decompostos para atingir o resultado final.

Através da interação verbal entre os alunos $E$ e $M$ percebe-se que o diferencial entre o resolver sozinho e com outros uma determinada atividade matemática está na possibilidade de discussão, questionamentos, contra-argumentações sobre as estratégias, e isso, conseqüentemente, favorece a ampliação e internalização de conceitos matemáticos tanto por quem fala quanto por quem ouve. Também pode ocorrer na interlocução entre ambos uma nova forma de resolver o problema que não estava presente antes, e assim são construídas novas estratégias para solucionar o problema. Na TCRA1, em particular, durante todo o processo de participação ambos se envolveram mutuamente na resolução dos problemas. Outro fator importante para a análise dessa tríade foi à reciprocidade de indicação na entrevista.

Desta maneira, infere-se que o grau de afetividade é um importante fator para impulsionar a interação entre os alunos, e, por conseguinte o diálogo, discussão, explicação, descrição, negociação das estratégias matemáticas flui de maneira mais clara e intensa.

Já as ENA encontradas foram $T E$ e $V C M$. Estas podem ser exemplificadas nos seguintes trechos dos diálogos:

Ex: TCRA2: $(T E)$

320. B: 5 reais.

321. J: mais como? se ela levou 5 reais

322. B: não sei.

323. J: ela levou 5 reais?

324. B: (explica) pois é tira daqui ó, e põe aqui, ah não errei, não sei.

325. J:(interrompe) não tô te dizendo 
325. B: (faz pauzinho) não pêra aí, 1,2,3,4,5-1,2,3,4,5,6,7,8 tira o 5 fica 1,2,3,4,5,6,7,8 fica 8 reais

326. J: oh meu Deus do céu!

327. B: umbora logo, então vê se dá? umbora aí!

328. J: (pega o lápis de B e faz pauzinho) 1,2,3,4,5,5 menos1,2,3,4,5,6,7,8,.

329. J:( bate com o lápis na cabeça de B) é 9

330. J: ah não sei, não sei essa pergunta (abaixa o lápis).

No trecho acima a relação dialógica entre $\mathrm{J}$ e B é mais intensa, e durante essa interação verifica-se a utilização da estratégia $T E$. A participante $B$ anuncia uma resposta por cálculo mental, entretanto, ao ser questionada por $J, B$ busca demonstrar com recursos gráficos como chegou ao resultado. Ao final da explicação J coloca em dúvida a resposta de B (e.g. 326), e B por não consegue explicitar claramente como chegou ao resultado e desiste de realizar o cálculo. Entretanto, nenhuma das duas alunas expressou claramente os meios pelos quais tentavam encontrar a resposta. Segundo Carvalho (2001) na estratégia por $T E$ os alunos tentam com diferentes estratégias encontrar o resultado, e partir das tentativas passam a verificar qual delas poderá corresponder ao valor pretendido.

TSRA3: (TE)

85. S: Quem ficou com menos figurinha no final do jogo?

86. H: Com menos?

87. S: Foi Pedro (apontando para o papel).

88. L: Foi (balançando a cabeça em sinal positivo).

89. S: Por que?

90. S: não sei!

91. L: Olha, não, foi o Marcelo que perdeu 5 e perdeu 4 e não ficou com nenhuma (olhou para " $H$ ").

92. H: não, não, olha aqui olha (apontando para o papel).

93. L: É, Pedro, é Pedro, Pedro (apontando para o papel).

Os alunos da TSRA3 anunciam várias respostas por cálculo mental, e na tentativa de oferecer diferentes respostas ao problema e aos colegas não explicaram claramente como chegaram à solução final. Através dessas tentativas de diferentes respostas verificou-se um contexto relacional com poucas oportunidades de interação entre os alunos.

Neste sentido, verifica-se que o aspecto afetivo observado através dos comportamentos, atitudes tanto frente a resolução dos problemas matemáticos quanto aos "outros" foram fundamentais para a construção de um contexto cooperativo e de co-construção nas TCRA. Já comportamentos competitivos e atitudes individualistas foram percebidos nas TSRA, isso foi um indicio claro de que o fator afetivo interferiu na relação entre os alunos e na própria estratégia matemática utilizada pelos mesmos. A estratégia $V C M$, por exemplo, foi utilizado com bastante frequiência nas TSRA2, TSRA3 e TSRA4. Abaixo segue um momento em que apareceu a estratégia VCM:

Ex: TSRA4: $(V C M)$

10. A: (Lê com dificuldade a questão) Para pintar a casa de cerca de plantas...

11. E: (interrompe e lê com rapidez e alto) Para pintar a casa de cerca de plantas o pintor gastou 8 latas de tinta. Ta aqui... escreve (Aponta para o papel).

12. I: Escreve o pintor gastou 8 latas de tinta. 
No exemplo acima se observa que o aluno $\mathrm{E}$ apresenta um resultado, mas não explica claramente como fez o cálculo, e seus colegas aceitam sem questionamentos o resultado, caracterizando desta forma a estratégia por $V C M$.

Em síntese, os resultados mostraram que as TCRA utilizaram tanto EA quanto ENA, o diferencial foi que as TCRA na maioria das vezes buscavam verbalizar para os outros quais as estratégias que estavam utilizando para chegar aos resultados, bem como havia discussão sobre a estratégia utilizada. Segundo Simão et al (2004) este envolvimento mútuo ocorre em função da representação que o participante tem do outro e do significado atribuído à tarefa. Neste sentido percebeu-se que a interação foi mais consistente e a participação guiada ocorreu mais freqüentemente entre TCRA, pois houve uma maior intersubjetividade, onde o vinculo afetivo foi maior.

Já nas TSRA as estratégias mais utilizadas foram as ENA, principalmente a $V C M$. Nestas tríades os cálculos eram realizados de forma individual, sem verbalização para o outro. $\mathrm{Ou}$ seja, o participante que estava resolvendo o problema não envolvia o outro na relação e desta forma não permitia que o mesmo tivesse acesso a suas estratégias de resolução da tarefa. Para Simão et al (2004) a relação de confiança e autoconfiança são aspectos fundamentais para se construir um ambiente de interação qualitativa, ou seja, um ambiente em que se construa o diálogo, discussão de pontos de vistas, bem como negociações e compartilhamento de significados entre os alunos de uma determinada tarefa são importantes para a apropriação de conhecimentos.

Rogoff (2005) nesta mesma linha enfatiza que o envolvimento ou não das pessoas em uma determinada tarefa está ligado às oportunidades, facilitações que outro ou o contexto lhe proporcionam. Caso isso seja limitado o participante terá mais dificuldade em apropriar-se dos conceitos trabalhados. Neste sentido infere-se que a apropriação de conhecimentos matemáticos acontece na medida em que o participante da tarefa está envolvido diretamente na resolução e quando o "outro" lhe proporciona acesso a suas estratégias, bem como está disponível para a explicação, discussão e negociação.

\section{Considerações Finais}

Os resultados apresentados demonstraram que a interação qualitativa entre tríades ocorreu onde os alunos atribuíram significados uns aos outros e a própria tarefa. Esse significado possibilitou interação verbal mais consistente e desenvolvimento cognitivo demonstrado através da construção, discussão de estratégias. Neste sentido, infere-se que num ambiente cooperativo e de co-construção de significados os alunos têm a oportunidade de demonstrar, negociar estratégias, construir e discutir sobre os processos que envolviam a resolução da tarefa.

A exemplo de como o grau de afetividade é importante para interação e construção de conhecimentos nas tríades de alunos, foi a utilização da estratégia $V C M$ pelas TSRA2, TSRA3 e TSRA4, que diminuiu consideravelmente seus envolvimentos e dos outros na tarefa. Nesse contexto os alunos tinham como meta apresentar sozinho o resultado.

Ao contrário, os alunos das TCRA estruturavam o envolvimento um dos outros na tarefa em razão da afetividade, essa estruturação foi observada quando os alunos buscavam explicitar verbalmente ou por escrito para o outro os caminhos que percorreram para chegar ao resultado. Essas demonstrações viabilizavam e interferiam na participação e construção de novas estratégias pelos envolvidos, bem como proporcionaram compartilhamento de significados. Desta maneira, quando diferentes parceiros se envolvem num esforço conjunto para resolver problemas matemáticos ambos tiram benefícios próprios não só sobre o tema do diálogo, mas também sobre si, sobre o outro e sua relação com ele, propiciando desta forma a 
apropriação de competências sociais, afetivas, cognitivas através da participação em tarefas matemáticas (OLIVEIRA, 2002; SIMÃO, 2003; CARVALHO, 2003).

Diante disso, infere-se que somente a distribuição espacial de alunos em tríades ou em grupos para resolver tarefas matemáticas não é suficiente para que estes possam se envolver num processo de interação, pois, o significado que o outro e a própria tarefa tem para cada participante são fundamentais para a construção de um contexto cooperativo. Neste contexto os objetivos que os alunos perseguem estão estreitamente vinculados entre si, de maneira que cada um pode alcançar os próprios objetivos se apenas os outros alcançarem os seus. Assim os resultados que cada um da tríade persegue são igualmente benéficos para os demais com quem está interagindo. Isso significa que a cooperação como contexto interativo favorece o alcance de objetivos comuns.

Nesse sentido, um contexto cooperativo, onde os alunos constroem significados conjuntos há maiores possibilidades de um maior envolvimento, discussão, argumentações, contraargumentações, e isso sem dúvida é benéfico não só para o desenvolvimento de competências matemáticas, mas sociais, afetivas, cognitivas e lingüísticas. Desta maneira cada participante regula e auto-regula suas ações e as dos outros para atingir um objetivo final que pode ser modificado no processo de interação.

Diante disso os resultados deste estudo e de outros nesta mesma linha, podem ser úteis na criação de condições mais efetivas de aprendizado e desenvolvimento da criança no que se refere tanto a educação matemática quanto nas relações interpessoais, pessoais e culturais, viabilizando uma maior compreensão do comportamento dos alunos e conseqüentemente desenvolvendo uma prática pedagógica voltada para a formação de atores críticos, capazes de relacionar os diversos conhecimentos nas situações do cotidiano.

\section{Referências}

CARVAlHO, C. Comunicações e Interações Sociais nas Aulas de Matemática. In: Seminário de Ensino da Matemática no âmbito da $14^{\circ}$ conferência realizada por COLE, 1 ., 2003. Anais... Campinas/SP, Julho de 2003.

Interaçção Entre Pares: Contributos para a promoção do Desenvolvimento Lógico e do Desempenho Estatístico no $7^{\circ}$ ano de Escolaridade. 2001.485 f. Tese (Doutorado em Educação) - Departamento de Educação da Faculdade de Ciências, Universidade de Lisboa, Lisboa. 2001.

CARVALHO, Carolina.; CÉSAR, Margarida. Interações Sociais, desenvolvimento Cognitivo e Matemática. In: Congresso da SPCE, 5., 2002, Porto. Anais. Porto: COLIBRI/SPCE, 2002. p. 407-416.

CÉSAR, Margarida. "Interacções sociais e apreensão de conhecimentos matemáticos: a investigação contextualizada". In: PONTE, J.P; SERRAZINA, L. (Ed.). Educação Matemática em Portugal, Espanha e Itália: Actas da Escola de Verão. Lisboa: Sociedade Portuguesa de Ciências da Educação, 2000, p. 05-46.

CORRÊA, J.; MOURA, M. L. S. A Solução de Problemas de Adição e Subtração por Cálculo Mental. Psicol. Reflex. Crit. V.10, n.10. Porto Alegre, 1997.

COSTA, E. V.; LYRA, M.C.D.P. Como a mente se torna social para Bárbara Rogoff? A questão da centralidade do sujeito. Psicol. Reflex. Crit., Porto Alegre, v. 15, n. 3, 2002. Disponível em: <http://www.scielo.br/scielo.php?. Acesso em: 5 Jun. 2007. 
FREITAS, Márcia B. A. Problemas de Adição e Subtração: Soluções em Diferentes Circunstâncias. Dissertação (Mestrado em Educação) - Curso de Pós-Graduação em Educação, Universidade Federal do Paraná, Curitiba, 2005.

GÓES, M.C.R. A abordagem Microgenética na Matriz histórico-cultural: Uma Perspectiva para o Estudo da Constituição da Subjetividade. Cadernos Cedes., n.50, Abril, 2000.

NEVES, M. C.; CARVALHO, C. A Importância da Afetividade na Aprendizagem da Matemática em Contexto Escolar: Um Estudo de Caso com Alunos do $8^{\circ}$ ano. Análise Psicológica, n. 2, p. 20-215, 2006.

OLIVEIRA, M.S.; SILVA, M.C.L.; MENDONÇA. Apropriação do Conhecimento através da Apropriação Guiada por Díades de Crianças na Resolução de Problemas Matemáticos com e sem Relação de Amizade. In: CONGRESSO NORTE-NORDESTE DE PSICOLOGIA, 5, 2007, Maceió. Anais... Maceió,Conselho Regional de Psicologia 2007.

OLIVEIRA, M. S. Construção de Conhecimento em Interações Verbais durante solução de Problemas Matemáticos: Uma análise semiótico-Construtivista. Revista Ciência, Educação e Cultura, Macapá, Unifap, v. 1, n.1, p. 25-50, dezembro, 2003.

OLIVEIRA, M. S.; TOURINHO, E. Z. Desempenho de Crianças do Ensino Fundamental na Solução de Problemas Aritméticos. Estudos de Psicologia, v.6, n.1, p. 63-74, 2001.

OLIVEIRA, M. S. Interação Verbal e Construção de Conhecimento por Díades de Crianças: Uma análise Segundo a Concepção Boeschiana de "Valor Visado" e "Valor Real". 2002. 176 f. Tese (Doutorado em Psicologia) - Instituto de Psicologia, Universidade de São Paulo, São Paulo. 2002.

ROGOFF, B. A Natureza Cultural do Desenvolvimento Humano. Porto Alegre: Artmed. 2005. Observando a Atividade Sociocultural em Três planos: Apropriação Participatória, Participação Guiada e Aprendizado. In: WERTSCH, J.; DEL RÍO, P.; ALVAREZ, A.(Orgs). Estudos Socioculturais da Mente. Tradução Maria da Graça Gomes Paiva e André Rossano Teixeira Camargo. Porto Alegre: Artmed, 1998. p. 123-142.

SANTOS, Roberta Rodrigues. O papel da Argumentação na Aprendizagem de Conceitos Matemáticos. In: SIMPÓSIO INTERNACIONAL DE PESQUISA EM EDUCAÇÃO MATEMÁTICA. Recife, Anais... Recife: Centro de Educação da Universidade Federal de Pernambuco, 2006, p. 9.

SIMÃO, L. M. et al. O Outro no Desenvolvimento Humano: Diálogos para a Pesquisa e a Prática Profissional em Psicologia. São Paulo: Pioneira Thomson Learning, 2004. (total de páginas, ex: 56p.)

SIMÃO, L. M. O Significado da Interação Verbal para os Processos de Construção de Conhecimento: Proposta a partir da Óptica Boeschiana. In: LEITE, S. A. (Org.). Cultura, Cognição e Afetividade: A Sociedade em Movimento. São Paulo: Casa do Psicólogo, 2002. p. 85-99. 
Interação Verbal e Construção de Conhecimento: Desenvolvimento a partir da Teoria da Ação Simbólica de Ernst Boesch. In: SIMPÓSIO: INTERAÇÃO, MODELOS EM DISCUSSÃO E CONFERÊNCIA DE PESQUISA SOCIOCULTURAL, 3., 2000, Campinas. Anais... Campinas, julho 2000.

SILVEIRA, M. R. A Resolução de Sentidos e Construção de Conceitos na Relação Ensino/aprendizagem da Matemática. 2005. 176 f. Tese (Doutorado em Educação) Faculdade de Educação, Universidade Federal do Rio Grande do Sul, Porto Alegre. 2005. 


\begin{abstract}
The objective of this research was to describe and analyze the strategies used by triads of students with and without regard for friendship during participation guided in Mathematical tasks. 24 students from the $3^{\text {rd }}$ grade of elementary school, grouped into four triads with regard for friendship (TCRA) and four triads without regard for friendship (TSRA) participated. The selection to group them occurred through interview searching to know the emotional bond. The interactions were recorded with video camera and recorder, later they were transcribed and analyzed. The results showed that the triads used many algorithm strategies (EA) that involved no algorithm rules and strategies (ENA) characterized by the absence of explicit Mathematical rules. The algorithm strategies (EA) were divided in oral and written. It was observed that as much as the TCRA as the TSRA used as common strategy of counting the fingers and the writing. The difference analyzed in the strategies was the use of ENA for mental calculation by TSRA, in other words, the students searched to resolve in an individual way and didn't express to their partners the strategies used, observing this way that the meaning given to the partner and to the task is what makes possible or not the interaction among the students.
\end{abstract}

Keywords: Mathematical strategies. Triads of students. Guided participation. Affectivity. 